\title{
Alterations in Glucose Metabolism Induce Hypothermia Leading to Tau Hyperphosphorylation through Differential Inhibition of Kinase and Phosphatase Activities: Implications for Alzheimer's Disease
}

\author{
Emmanuel Planel, ${ }^{1}$ Tomohiro Miyasaka, ${ }^{1}$ Thomas Launey, ${ }^{2}$ De-Hua Chui, ${ }^{1}$ Kentaro Tanemura, ${ }^{1}$ Shinji Sato, ${ }^{1}$ \\ Ohoshi Murayama, ${ }^{3}$ Koichi Ishiguro, ${ }^{4}$ Yoshitaka Tatebayashi, ${ }^{1}$ and Akihiko Takashima ${ }^{1}$ \\ ${ }^{1}$ Laboratory for Alzheimer's Disease and ${ }^{2}$ Laboratory for Memory and Learning, Brain Science Institute, The Institute of Physical and Chemical Research, \\ Wako-shi, Saitama 351-0198, Japan, ${ }^{3}$ Laboratory of Molecular Biology, School of Environmental Health Sciences, Azabu University, Sagamihara, Kanagawa \\ 229-8501, Japan, and ${ }^{4}$ Mitsubishi Kagaku Institute of Life Sciences, Machida-shi, Tokyo 195-8511, Japan
}

\begin{abstract}
Alzheimer's disease (AD) brains contain neurofibrillary tangles (NFTs) composed of abnormally hyperphosphorylated tau protein. Regional reductions in cerebral glucose metabolism correlating to NFT densities have been reported in AD brains. Assuming that reduced glucose metabolism might cause abnormal tau hyperphosphorylation, we induced in vivo alterations of glucose metabolism in mice by starvation or intraperitoneal injections of either insulin or deoxyglucose. We found that the treatments led to abnormal tau hyperphosphorylation with patterns resembling those in early AD brains and also resulted in hypothermia. Surprisingly, tau hyperphosphorylation could be traced down to a differential effect of low temperatures on kinase and phosphatase activities. These data indicate that abnormal tau hyperphosphorylation is associated with altered glucose metabolism through hypothermia. Our results imply that serine-threonine protein phosphatase $2 \mathrm{~A}$ plays a major role in regulating tau phosphorylation in the adult brain and provide in vivo evidence for its crucial role in abnormal tau hyperphosphorylation in AD.
\end{abstract}

Key words: Alzheimer's disease; hypothermia; tau hyperphosphorylation; glucose metabolism; insulin; diabetes mellitus; kinase; serinethreonine protein phosphatase; GSK-3; cdk5; JNK; MAPK

\section{Introduction}

The two histopathological hallmarks of Alzheimer's disease (AD) are senile plaques, composed of extracellular aggregates of the $\beta$-amyloid peptide $(\mathrm{A} \beta)$, and intraneuronal neurofibrillary tangles (NFTs), composed of abnormally hyperphosphorylated tau protein assembled in paired helical filaments (PHFs). Tau hyperphosphorylation induces PHF formation in vitro and is thought

Received 0ct. 21, 2003; revised Jan. 15, 2004; accepted Jan. 15, 2004.

This work was supported in part by Core Research for Evolutional Science and Technology, Japan Science and Technology, a Grant-in-Aid for Scientific Research on Priority Areas (Japanese Ministry of Education, Science, and Culture), and a Grant-in-Aid for Scientific Research (11680746; Japanese Ministry of Education, Science, and Culture). We are deeply indebted to Drs. Luc Buée, Charles Duyckaerts, and Dick F. Swaab for critical comments and discussions on this work. We are grateful to Bonnie LaMadeleine and Dr. Cynthia L. Dolorfo for editing this manuscript and to Sumihiro Maeda, Takumi Yamagishi, and Tatsuya Mizoroki for help with experiments. We thank Takahiro Kanegae and the staff of the Brain Science Institute Animal Facility for assistance with the animals. We also thank Drs. Shinobu C. Fujita, Mariko Kobayashi, and Yasuhiro Okawa for helpful comments in the initial stage of this work.

Correspondence should be addressed to Dr. Akihiko Takashima, Laboratory for Alzheimer's Disease, Brain Science Institute, The Institute of Physical and Chemical Research, 2-1 Hirosawa, Wako-shi, Saitama 351-0198, Japan. E-mail: kenneth@brain.riken.go.jp.

T. Miyasaka's present address: Department of Neuropathology, Faculty of Medicine, University of Tokyo, 7-3-1 Hongo, Bunkyo-ku, Tokyo 113-0033, Japan.

S. Sato's present address: Division of Cell Cycle Regulation, Cancer Research Institute, Kanazawa University, Kanazawa, Ishikawa 920-0934, Japan.

DOI:10.1523/JNEUROSCI.5561-03.2004

Copyright $\odot 2004$ Society for Neuroscience $\quad$ 0270-6474/04/242401-11\$15.00/0 to be a critical event in the pathogenesis of $\mathrm{AD}$ (Alonso et al., 2001; Sato et al., 2002). However, the causes of tau hyperphosphorylation in $\mathrm{AD}$ are poorly understood.

$\mathrm{AD}$ brains have been widely reported to display regional reductions in glucose metabolism (Frey et al., 1998), and these reductions have been shown to be correlated to NFT densities (DeCarli et al., 1992; Mielke et al., 1996; Stein et al., 1998). Interestingly, the cerebellum is not affected by reduced metabolism and is devoid of NFTs (Kushner et al., 1987; Larner, 1997). From these evidences, we hypothesized that in vivo alterations in glucose metabolism might be a potential cause of tau hyperphosphorylation. Previous reports demonstrating that modulations of glucose or insulin levels alter tau antigenicity in neuronal cultures support this hypothesis (Cheng and Mattson, 1992; Hong and Lee, 1997; Lesort et al., 1999). We also reported that starvation, which decreases the amount of circulating glucose and insulin and lowers glucose utilization (Newsholme, 1976; Cherel et al., 1988), induces AD-like tau hyperphosphorylation in mice (Yanagisawa et al., 1999; Planel et al., 2001).

To test our hypothesis, we investigated the causes of tau phosphorylation in starvation and in two in vivo paradigms known to alter glucose metabolism: intraperitoneal injections of insulin or 2-deoxy-D-glucose (DG). This experimental planning allowed us to discern the respective impacts of glucose, insulin, and glucose 
metabolism. Overdoses of insulin depress glucose metabolism through acute hypoglycemia (Auer and Siesjo, 1993). In contrast, administration of DG results in acute inhibition of metabolism while producing hyperglycemia with little effect on insulinemia (Horton et al., 1973).

All of the treatments led to tau hyperphosphorylation with a biochemical, histological, and regional pattern similar to that reported in early AD. Administration of glucose during starvation and insulin treatments could prevent tau hyperphosphorylation. Surprisingly, it was changes in body temperature, not direct alterations in glucose metabolism per se, that contributed to tau hyperphosphorylation by differentially inhibiting serinethreonine (Ser-Thr) protein phosphatase (PP) 2A (PP2A) and kinase activities. These results demonstrate that alterations in glucose metabolism induce hypothermia leading to tau hyperphosphorylation. The implications of these findings for Alzheimer's disease and the analysis of tau phosphorylation in laboratory animals are discussed here.

\section{Materials and Methods}

Animals

Eight- to twelve-week-old C57BL/6NJcl male mice (Clea, Tokyo, Japan) were used. Animals were handled according to procedures approved by the Animal Care and Use Committee of the Institute of Physical and Chemical Research.

\section{Alterations of glucose metabolism}

Starvation was performed as reported previously (Planel et al., 2001). To investigate the effect of glucose, food was similarly withheld from four mice, but they had free access to a $30 \%$ glucose solution. Note that in all of our experiments, food deprivation was absolute. It was not chronic caloric restriction and was consistent with conditions outlined in the Animal Welfare Act.

Insulin injections. Four nonfasted mice were injected intraperitoneally with $300 \mathrm{IU} / \mathrm{kg}$ of insulin (bovine pancreas insulin; Sigma, St. Louis, $\mathrm{MO})$ dissolved in saline. Food was withheld during the experiment. Control mice were similarly injected with saline. To investigate the effect of concomitant injection of insulin and glucose, a solution composed of 300 $\mathrm{IU} / \mathrm{kg}$ of insulin and $4.5 \mathrm{gm} / \mathrm{kg}$ of glucose in saline was injected in four additional animals. After $2.5 \mathrm{hr}$, brains were collected, prepared, and analyzed as described below. Note that in the literature, the amounts of insulin injected in mice to study the effects of hypoglycemia on the CNS vary from 2 to $300 \mathrm{IU} / \mathrm{kg}$ (Gorell et al., 1981; McCandless, 1981). We used the highest reported amount to be certain to obtain brain hypoglycemia.

Deoxyglucose injections. Four nonfasted mice were injected intraperitoneally with $4.5 \mathrm{gm} / \mathrm{kg}$ of DG (Sigma) dissolved in saline. For control conditions, saline or $4.5 \mathrm{gm} / \mathrm{kg}$ of glucose in saline was injected in two additional batches of four animals. After $1 \mathrm{hr}$, brains were collected, prepared, and analyzed as described below. Note that DG has been injected in fasted mice at $3.0 \mathrm{gm} / \mathrm{kg}$ to study its effects on brain glucose metabolism (Horton et al., 1973). Because our animals were nonfasted, they were injected with a $50 \%$ higher concentration.

\section{Plasma glucose and insulin quantification}

Plasma glucose was determined using the mutarotase-glucose oxydase method according to the manufacturer instructions (Autokit Glucose; Wako Chemicals, Osaka, Japan). Plasma insulin was determined using a sandwich enzyme immunoassay according to the manufacturer instructions (Mouse Insulin Kit; Shibayagi, Guhma, Japan).

\section{Protein extraction and SDS-PAGE}

Mice were killed by cervical dislocation, brains were immediately removed, and tissues were dissected in ice-chilled saline. Hemispheres (hippocampus and neocortex) or cerebella were quickly weighted, frozen on dry ice, and homogenized later in five times the volume-weight of modified radioimmunoprecipitation assay buffer $(50 \mathrm{~mm}$ Tris- $\mathrm{HCl}, \mathrm{pH}$ 7.4, $1 \%$ NP-40, 0.25\% Na-deoxycholate, $150 \mathrm{~mm} \mathrm{NaCl}, 1$ mм EDTA, 1 mм PMSF, $1 \mathrm{~mm} \mathrm{Na} \mathrm{VO}_{4}, 1 \mathrm{~mm} \mathrm{NaF}, 1 \mu \mathrm{g} / \mathrm{ml}$ of aprotinin, leupeptin, and pepstatin, $1 \mu \mathrm{M}$ okadaic acid), with a mechanical microhomogenizer (Physcotron NS-310E; Microtek, Chiba, Japan). Samples were then centrifuged for $20 \mathrm{~min}$ at $100,000 \times g$ at $4^{\circ} \mathrm{C}$, and protein content of the supernatants was determined. Depending on the antibody used, 7-14 $\mu \mathrm{g}$ of protein were analyzed as described previously (Planel et al., 2001).

\section{Antibodies}

Purified rabbit polyclonal anti-tau antibodies PS199, PS396, PS404, and Tau-C were described previously (Ishiguro et al., 1995; Sato et al., 2002). PT231, PS262, and PS422 were from Biosource International (Camarillo, CA). Anti-MAP2 was a generous gift from Dr. Yasuo Ihara (Tokyo University, Tokyo, Japan). Various monoclonal anti-tau antibodies were also used: Tau (Becton Dickinson, Rutherford, NJ) recognizes a phosphoindependent epitope, AT8 (Innogenetics, Geut, Belgium) reacts with tau phosphorylated at S202 and T205 (Goedert et al., 1995), AT100 (Innogenetics) recognizes tau phosphorylated at T212 and S214 (ZhengFischhofer et al., 1998), and Tau-1 (Chemicon, Temecula, CA) recognizes tau dephosphorylated at S195, S198, S199, and S202 (Szendrei et al., 1993). Changes in tau kinases were investigated with the following antibodies: cyclin-dependant kinase 5 (cdk5) (Santa Cruz Biotechnology, Santa Cruz, CA), glycogen synthase kinase- $3 \beta$ (GSK-3 $\beta$ ) (BD Transduction Laboratories), anti-GSK-3 $\alpha / \beta$ (pY219/pY216; Biosource International), phospho-GSK-3 $\beta$ (Ser9), stress-activated protein kinase (SAPK)/c-Jun N-terminal protein kinase (JNK), phospho-SAPK/JNK (T183/Y185) G9, p44/42 MAP kinase, phospho-p44/42 mitogenactivated protein kinase (MAPK) (T202/Y204) (Cell Signaling Technology, Beverly, MA), and anti-p35C (Ohshima et al., 2001). See Table 1 for more information.

\section{Western blot analysis}

Membrane blocking and antibody incubations were done according to a Cell Signaling Technology MAPK immunoblotting protocol (number 9102), with appropriate primary and secondary antibody dilutions. Antimouse and anti-rabbit HRP-conjugated secondary antibodies were purchased from Santa Cruz Biotechnology or Jackson ImmunoResearch (West Grove, PA). Immunoreactive bands were visualized and analyzed as described previously (Planel et al., 2001). Serial dilutions of brain extracts were loaded into gels to obtain calibration curves allowing reliable quantification.

\section{Immunohistochemistry}

Tissue fixation was done according to the "cold Bouin's method" recently developed in our laboratory. This procedure minimizes postmortem tau dephosphorylation in mice brains (our unpublished observations). Briefly, mice were anesthetized and transcardially perfused with PBS at room temperature. The brain was quickly removed and immersed in ice-cold Bouin's solution (saturated picric acid, formalin, acetic acid at 15:5:1) for $24 \mathrm{hr}$ and embedded in paraffin blocks. Eight to ten micrometer thick sections were processed for immunohistochemical analyses. Deparaffinized and hydrated sections were incubated in Target Retrieval Solution (Dako, Carpinteria, CA) at $70^{\circ} \mathrm{C}$ for $25 \mathrm{~min}$ for enhancement of the immunoreactivity and then incubated in $10 \%$ normal goat serum in PBS at $4^{\circ} \mathrm{C}$ for $2 \mathrm{hr}$. The specimens were incubated in primary antibodies diluted in $1 \%$ BSA in PBS containing $0.05 \%$ Tween 20 overnight at $4^{\circ} \mathrm{C}$. Bound antibodies were visualized with Alexa 488-conjugated anti-mouse or Alexa 568-conjugated anti-rabbit IgG (Molecular Probes, Eugene, OR). Immunolabeled tissues were observed under an Olympus (Tokyo, Japan) BX50 microscope equipped with an Olympus DP50 digital CCD camera and Studio Lite 1.0 software (Pixera, Tokyo, Japan) or a Radiance 2000 KR3 laser scanning confocal imaging system equipped with the Lasersharp 2000 software (Bio-Rad, Hercules, CA).

\section{Acute mouse brain slices}

Metabolically active brain slices were prepared according to a modified protocol from Gong et al. (2001). Briefly, mice were killed by cervical dislocation, brains were immediately removed, and hemispheres (hippocampus and neocortex) were quickly chopped in $400 \mu \mathrm{m}$ thick coronal slices. The slices were immediately transferred into chambers containing oxygenated DMEM (Invitrogen, San Diego, CA) with $25 \mathrm{~mm}$ glucose at $37^{\circ} \mathrm{C}$. After $30 \mathrm{~min}$ of recovery, the slices were transferred into 
Table 1. Antibodies used in this study

\begin{tabular}{|c|c|c|c|c|c|c|}
\hline Name & Abbreviation & Epitope or immunogen & Type & WB & $\mathrm{IHC}$ & Origin \\
\hline \multicolumn{7}{|l|}{ MAPs } \\
\hline $\mathrm{Tau} 1^{a}$ & Tau-1 & S195, S198, S199, S202 & Mouse $\lg G 2 a$ & $1 / 1000$ & $1 / 400$ & Chemicon \\
\hline Anti-PS199 & PS199 & pS199 & Rabbit polyclonal & $1 / 2500$ & $1 / 400$ & K. Ishiguro \\
\hline AT8 & AT8 & pS202, pT205 & Mouse lgG1k & $1 / 1000$ & $1 / 400$ & Innogenetics \\
\hline $\mathrm{AT}_{100^{b}}$ & AT100 & pS212, pT214 & Mouse lgG1k & $1 / 500$ & $1 / 200$ & Innogenetics \\
\hline Anti-tau [pT231] & PT231 & pT231 & Rabbit polyclonal & $1 / 5000$ & $1 / 400$ & Biosource international \\
\hline Anti-tau [pS262] & PS262 & pS262 & Rabbit polyclonal & $1 / 5000$ & $C R$ & Biosource International \\
\hline Anti-PS396 & PS396 & pS396 & Rabbit polyclonal & $1 / 1000$ & $1 / 400$ & K. Ishiguro \\
\hline Anti-PS404 & PS404 & pS404 & Rabbit polyclonal & $1 / 1000$ & $1 / 200$ & K. Ishiguro \\
\hline Anti-Tau [p\$422] $]^{b}$ & PS422 & pS422 & Rabbit polyclonal & $1 / 5000$ & $C R$ & Biosource International \\
\hline Anti-Tau-C & Tau-C & hTau 422-438 & Rabbit polyclonal & $1 / 5000$ & $C R$ & A. Takashima \\
\hline Tau & Tau & hTau 23-179 & Mouse $\lg G 2 \mathrm{~b}$ & $1 / 1000$ & $1 / 400$ & BD Transduction Laboratories \\
\hline Anti-MAP2 & MAP2 & hMAP2 & Rabbit polyclonal & NU & $1 / 500$ & Y. Ihara \\
\hline \multicolumn{7}{|l|}{ KINASES } \\
\hline Cdk5 (C8) & Cdk5 & human Cdk5 C-terminus & Rabbit polyclonal & $1 / 1000$ & NU & Santa Cruz Biotechnology \\
\hline GSK-3 $\beta$ & GSK-3 $\beta$ & rat GSK-3 $\beta$ 1-160 & Mouse lgG1 & $1 / 2500$ & NU & BD Transduction Laboratories \\
\hline Anti-GSK-3 $\alpha / \beta$ [pY279/216] & PY216 & GSK-3 $\alpha / \beta$ pY279/Y216 & Rabbit polyclonal & $1 / 1000$ & NU & Biosource International \\
\hline Phospho-GSK-3 $\beta$ (Ser9) & PS9 & GSK-3 $\beta$ pS9 & Rabbit polyclonal & $1 / 1000$ & NU & Cell Signaling Technology \\
\hline SAPK/JNK & JNK & human JNK2 & Rabbit polyclonal & $1 / 1000$ & NU & Cell Signaling Technology \\
\hline Phospho-SAPK/JNK (T183/Y185) G9 & p-JNK & p-JNK T181/Y185 & Mouse $\lg \mathrm{G} 1$ & $1 / 2000$ & NU & Cell Signaling Technology \\
\hline p44/42 MAP Kinase & MAPK & rat p42 MAPK & Rabbit polyclonal & $1 / 1000$ & NU & Cell Signaling Technology \\
\hline Phospho-p44/42 MAPK (T202/Y204) & p-MAPK & p-MAPK T202/Y204 & Rabbit polyclonal & $1 / 1000$ & NU & Cell Signaling Technology \\
\hline Anti-p35C & p35 & recognizes p35 and p25 & Rabbit polyclonal & $1 / 500$ & NU & K. Ishiguro \\
\hline
\end{tabular}

WB, Dilution used for Western blotting; IHC, dilution used for immunohistochemistry; NU, not used; CR, cross-react with MAP2.

${ }^{a}$ Tau-1 is specific to dephosphorylated tau at the indicated epitopes.

${ }^{b}$ Pathological epitope.

others chambers with oxygenated DMEM at various temperatures or with different concentrations of glucose or deoxyglucose. At the end of the experiment, slices were individually collected, quickly frozen on dry ice, and processed as indicated above for Western blot analysis. There was no indication of cell death during exposure at different temperatures (data not shown).

\section{Ser-Thr protein phosphatase activities}

The direct effect of temperature on phosphatase activities was performed using the serine-threonine phosphatase assay system from Promega (V2460; Promega, Madison, WI). Briefly, a normal mouse was killed by cervical dislocation, the brain was immediately removed, one hemisphere (hippocampus and neocortex) was homogenized in five times the volume-weight of phosphatase sample buffer (Planel et al., 2001), and immediately processed as indicated by the manufacturer to remove particulate matter and endogenous free phosphate. For PP2A activity, $2.5 \mu \mathrm{l}$ of the resulting solution was prepared in triplicates for each temperature $\left(37,30,23,15\right.$, and $\left.1^{\circ} \mathrm{C}\right)$, and the release of phosphate from a chemically synthesized phosphopeptide was assessed over a period of $15 \mathrm{~min}$ in protein phosphatase (PPT) -2A buffer (calibration data not shown). The amount of phosphate released was measured by the absorbance of the molybdate-malachite green-phosphate complex at $595 \mathrm{~nm}$. We also assayed PP2B activity in the same conditions over $30 \mathrm{~min}$ in PPTase-2B buffer in the presence of $50 \mathrm{~nm}$ okadaic acid to inhibit PP2A activity.

\section{Brain tau kinase activity}

The direct effect of temperature of tau kinase activity was assayed as described previously (Planel et al., 2001) with modifications. Briefly, $1 \mu \mathrm{l}$ of fresh modified RIPA brain extract $(5 \times \mathrm{v} / \mathrm{w})$ was added to $50 \mu \mathrm{l}$ of modified Tau phosphorylation mixture $(200 \mu \mathrm{g} / \mathrm{ml}$ human full-length recombinant tau; $1 \mathrm{~mm}$ ATP, $10 \mathrm{~mm}$ Tris-HCl, $\mathrm{pH}$ 7.0, $2 \mathrm{~mm}$ 2-mercaptoethanol, $2 \mathrm{~mm} \mathrm{Mg}$ acetate, $2 \mathrm{~mm}$ EGTA, $1 \mathrm{~mm} \mathrm{NaF}, 1 \mathrm{~mm}$ $\mathrm{Na}_{3} \mathrm{VO}_{4}, 1 \mathrm{~mm}$ PMSF, $1 \mu \mathrm{M}$ okadaic acid, $1 \mu \mathrm{g} / \mathrm{ml}$ aprotinin, leupeptin, and pepstatin) and incubated for $15 \mathrm{~min}$ (calibration data not shown) in triplicates for each temperature $\left(37,30,23,15\right.$, and $\left.1^{\circ} \mathrm{C}\right)$. The reaction was terminated by adding $50 \mu \mathrm{l}$ of $\mathrm{O}+$ buffer (Planel et al., 2001) and boiling for $5 \mathrm{~min}$. The activity of brain kinases toward recombinant tau was assayed by quantitative immunoblotting using anti-tau PS404, as described previously (Planel et al., 2001). PS404 is an epitope phosphorylated by most of the major tau kinases (Planel et al., 2002).

\section{Statistical analysis}

Statistical analysis was performed by ANOVA for all data except in Figure 2. Significant factors from ANOVA $(p<0.05)$ were followed by the Tukey-Kramer test of pair-wise multiple comparisons. Data are means $\pm \mathrm{SD}$; asterisks indicate significant differences, with ${ }^{\star} p<0.05$ and ${ }^{* *} p<0.01$.

\section{Results}

\section{Starvation, insulin, and deoxyglucose treatments induce PHF-like tau hyperphosphorylation}

We first analyzed the relationship between starvation and glucose metabolism. To this end, starved mice were given free access to a $30 \%$ glucose solution. Three days of food deprivation induced the hyperphosphorylation of tau at all sites studied, including AT100 and PS422, whereas the amount of total tau remained unchanged (Fig. $1 A, B$, lanes 1 and 2), confirming and extending our previous results (Planel et al., 2001). Phosphorylation at these two epitopes is characteristic of AD-like tau phosphorylation (Matsuo et al., 1994; Hasegawa et al., 1996; Bussiere et al., 1999). A characteristic shift in the separation pattern of total tau toward a major band at $60 \mathrm{kDa}$ and two minor bands at 68 and $74 \mathrm{kDa}$ was observed (Fig. $1 \mathrm{Aj}$; see Fig. 2 for apparent molecular masses). Access to glucose virtually prevented tau hyperphosphorylation (Fig. 1 A, B, lane 3), indicating that starvation-induced tau hyperphosphorylation probably stems from carbohydrate deprivation rather than a lack of vitamins, ions, or proteins.

Injections of insulin led to a pronounced tau hyperphosphorylation at $2.5 \mathrm{hr}$. The electrophoretic separation pattern of hyperphosphorylated tau was similar to that observed in starvation, except that AT100 immunoreactivity was very weak (Fig. 1C,D, lanes 1 and 2). Again, access to glucose, administered by concomitant injections at $4.5 \mathrm{gm} / \mathrm{kg}$, prevented most of the hyperphos- 

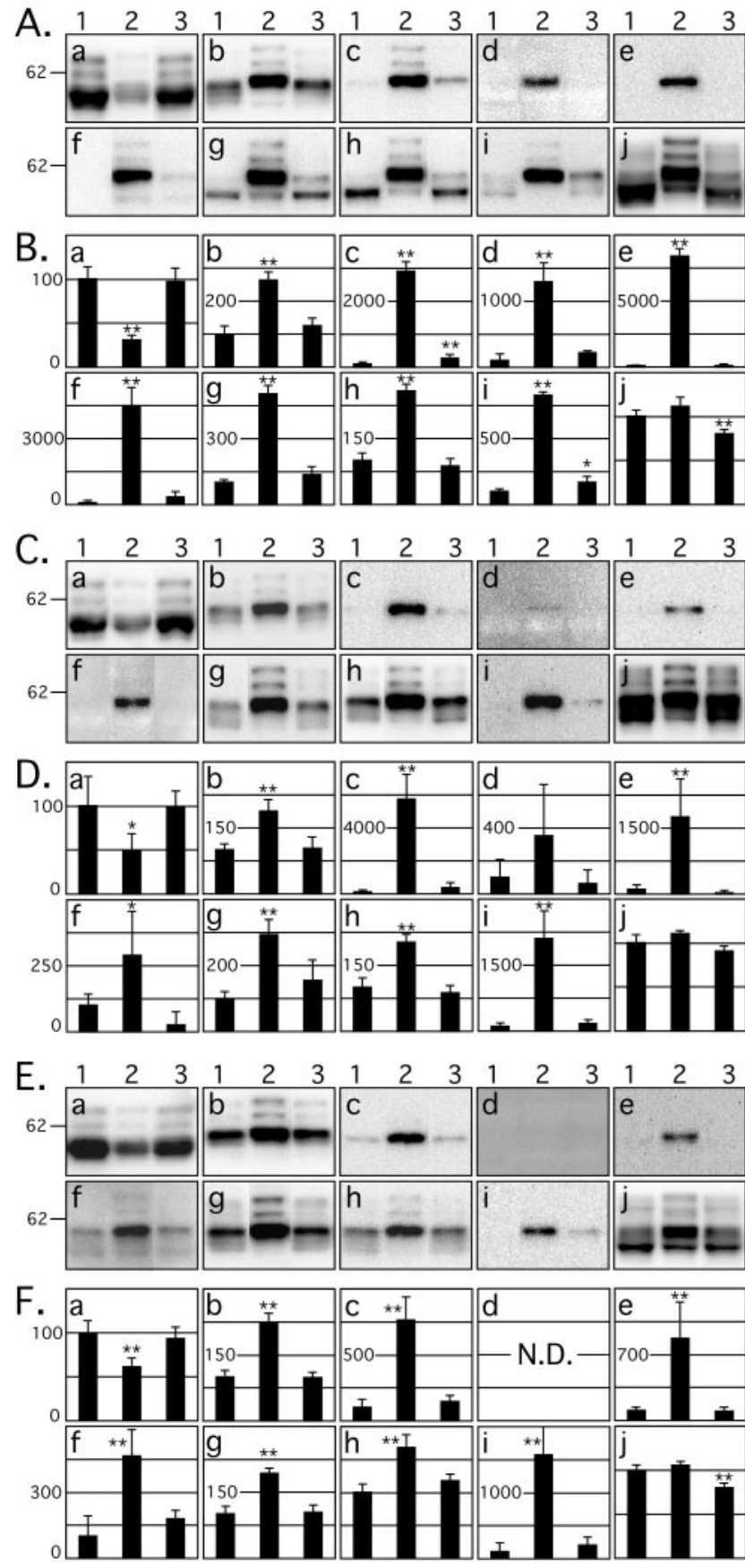

Figure 1. Western blot analysis of tau phosphorylation during alterations of glucose metabolism. Proteins from mouse brain extracts (hippocampus plus neocortex) were separated by SDS-PAGE and identified with the following antibodies: $a$, Tau-1; $b$, PS199; $c$, AT8; $d$, AT100; $e$, PT231; f, PS262; $g$, PS396; $h$, PS404; $i$, PS422; $j$, Tau-C. Each lane shows an immunoblot extract from one representative mouse of four analyzed. $A$, Immunoblots from starved condition. Lane 1, Samples from fed control mice; lane 2, samples from mice starved for $3 \mathrm{~d}$; lane 3, samples from mice starved for $3 \mathrm{~d}$ but given access to a $30 \%$ glucose solution. C, Insulin condition. Lane 1, Saline-injected control mice; lane 2, insulin-injected mice; lane 3, mice injected with a mixture of insulin and glucose. E, DG condition. Lane 1, Saline-injected control mice; lane 2, DG-injected mice; lane 3 , glucose-injected mice. $B, D$, and $F$ represent the quantification of immunoblot bands in $A, C$, and $E$, respectively. Data are means ( $n=4$ for each condition) \pm SD. Asterisks indicate significant differences from controls, with ${ }^{*} p<0.05$ and ${ }^{* *} p<0.01$. Each graph displays the immunoreactivity expressed as a percentage of the control lane 1 (100\%). Numbers in the graphs indicate the percentage of the line with which they are aligned. N.D., Not determined.
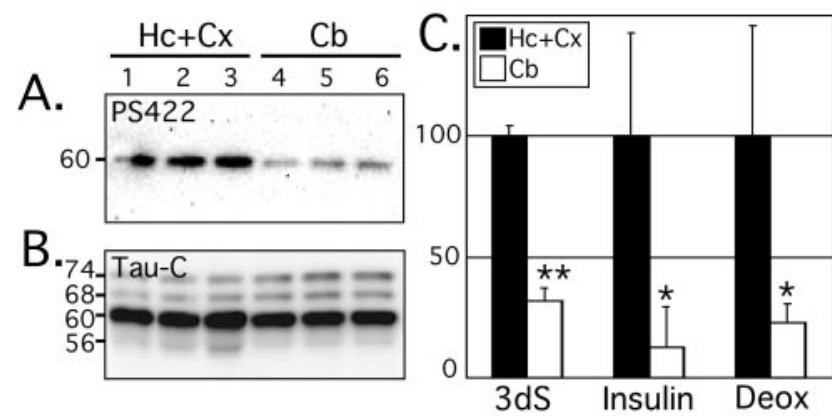

Figure 2. Tau phosphorylation in the cerebellum during alterations in glucose metabolism. Western blot analysis of mouse hippocampal-neocortical extracts $(\mathrm{Hc}+\mathrm{Cx})$ and cerebellar extracts (Cb) is shown. $A$, Immunoblot of the PS422 epitope (same lane assignments as in $B ; 3$ replicate experiments). $B$, Immunoblot of Tau- $\mathrm{C}$ from $\mathrm{Hc}+\mathrm{Cx}$ (lanes 1-3) and from $\mathrm{Cb}$ (lanes $4-6)$, both from 3-d-starved mice. C, Quantification of regional differences. The intensities of PS422 bands were normalized by total Tau-C and expressed as a percentage of the $\mathrm{HC}+\mathrm{CX}$ fraction for each of the conditions (3-d-starved, insulin, and deoxyglucose-injected). Immunoblot data are not shown for insulin and deoxyglucosetreatments. Statistical analysis was performed with Student's $t$ test. Data are means $(n=3$ per condition) $\pm S D$. Asterisks indicate significant differences from controls, with ${ }^{*} p<0.05$ and ${ }^{* *} p<0.01$. Deox, Deoxyglucose.

phorylation at all sites probed (Fig. 1C,D, lane 3), suggesting that phosphorylation is not mediated by hyperinsulinemia. Therefore, the alterations of glucose metabolism resulting from insulin injections are associated with tau hyperphosphorylation and can be prevented by concurrent injections of glucose.

To further investigate the effects of alterations of glucose hypometabolism on tau phosphorylation, we used DG, a glucose analog that is transported through the blood-brain barrier and inhibits glycolysis and oxidative metabolism of glucose. Unlike starvation or insulin injections, DG directly inhibits glucose metabolism and produces hyperglycemia (Horton et al., 1973). Injections of DG ( $4.5 \mathrm{gm} / \mathrm{kg}$, i.p.) induced tau hyperphosphorylation in a pattern similar to that induced by starvation (Fig. $1 E, F$, lanes 1 and 2), and control injections of glucose ( $4.5 \mathrm{gm} / \mathrm{kg}$, i.p.) failed to induce tau hyperphosphorylation (Fig. 1E,F, lane 3). This suggests that tau hyperphosphorylation is not mediated through hyperglycemia. AT100 immunoreactivity was absent, and total tau levels remained unchanged in response to DG treatment. These results demonstrate that disruption of glucose metabolism by DG leads to tau hyperphosphorylation.

Starvation, insulin, and deoxyglucose treatments induced a PHF-like tau hyperphosphorylation that could be prevented by glucose administration during starvation and insulin injections, demonstrating the involvement of reduced glucose metabolism as a cause of tau phosphorylation.

Tau hyperphosphorylation is lower in the cerebellum than in the neocortex

There are no NFTs in the cerebellum in AD. Therefore, we investigated whether there could be regional differences in tau phosphorylation during the treatments. We examined tau phosphorylation at the pS422 site in cerebellar $(\mathrm{Cb})$ and hippocampocortical extracts $(\mathrm{Hc}+\mathrm{Cx})$. The pS422 epitope is a pathological phosphoepitope (Hasegawa et al., 1996; Bussiere et al., 1999) and was hyperphosphorylated in all conditions tested. In food-deprived mice, tau hyperphosphorylation at pS422 in $\mathrm{Cb}$ extracts was $32 \%$ of that in $\mathrm{Hc}+\mathrm{Cx}$ extracts (Fig. $2 A, B$ ). In insulin- and DG-injected mice, tau hyperphosphorylation at pS422 in Cb extracts was 12 and 23\%, respectively, of that in $\mathrm{Hc}+\mathrm{Cx}$ extracts (Fig. $2 \mathrm{C}$; blots not shown). Therefore, hyperphosphorylation of tau after changes in glucose 

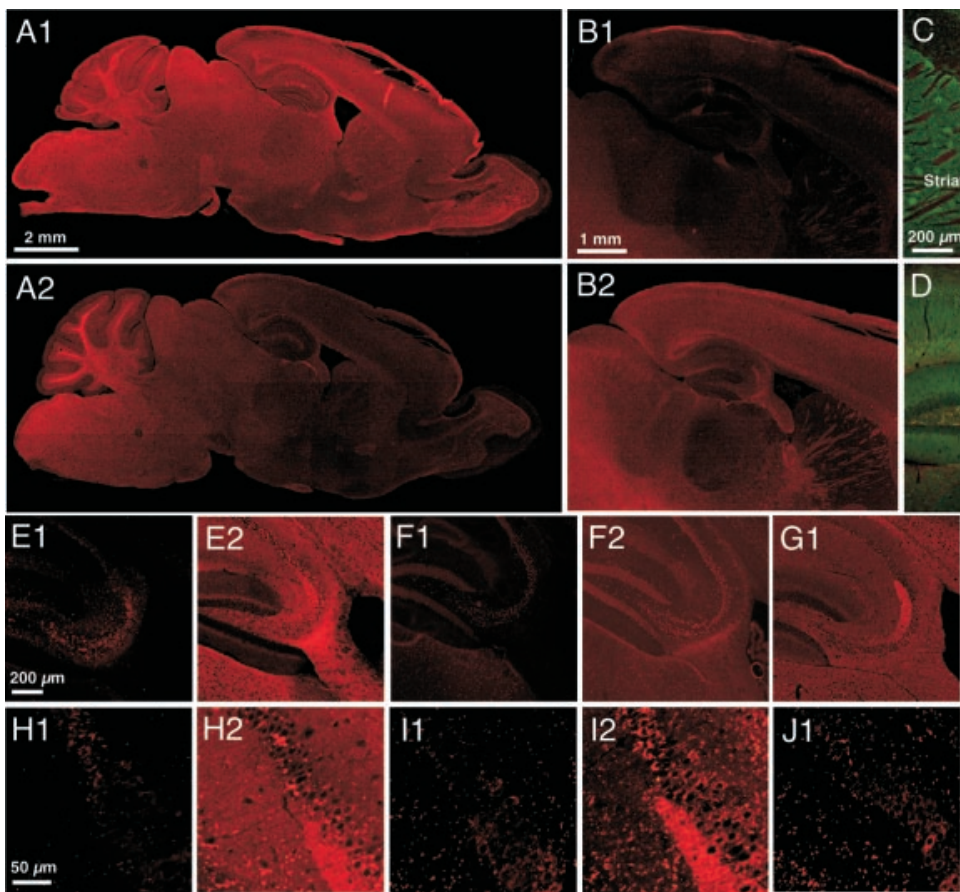

Figure 3. Regional anatomical analysis of tau hyperphosphorylation. Fluorescence photomicrographs of sagittal sections are shown. A, Tau-1 (dephosphorylated tau) immunoreactivity in control (A1) and starved (A2) mouse. B, AT8 immunostaining in control (B1) and starved (B2) mouse. C, D, During starvation, tau hyperphosphorylation was localized in the axons of the cortex, corpus callosum, and striatum ( $C$, and in the mossy fibers, alveus, and fimbria of the hippocampus $(D)$, as demonstrated by double immunostaining with AT8 (red) and MAP2 (green). E1-G2 display tau immunoreactivity at different epitopes in the hippocampal region of a control mouse (1) or food-deprived mouse (2). E, AT8. F, AT100. G, Total tau. H1-J2 display AT8 immunoreactivity at the CA1-CA2 border region and mid-distal part of CA3 in control mice $(H 1, I 1, J 1)$, starved mice $(H 2)$, or mice injected with either insulin (I2) or deoxyglucose (J2).

metabolism was threefold to eightfold lower in the cerebellum than in the hippocampus and cerebral cortex.

\section{Alterations in glucose metabolism induce axonal tau hyperphosphorylation}

We then examined the gross anatomical pattern of tau phosphorylation. Three days of starvation led to tau hyperphosphorylation at Tau-1 and AT8 epitopes in most anterior areas, such as the neocortex and hippocampus (Fig. 3A1,A2,B1,B2). Tau hyperphosphorylation was less robust in the cerebellum (Fig. $3 A 1, A 2)$. Hyperphosphorylated tau preferentially localized in axon tracts of cortical and hippocampal regions, as demonstrated by double immunostaining with AT8 and MAP2 antibodies in the starved mice (Fig. 3C,D). The pattern of tau hyperphosphorylation was striking in the hippocampus: mossy fibers and axons in the fimbria and alveus were intensely AT8 immunoreactive (Fig. 3 D, E1,E2). Hippocampal immunostaining with other phosphotau site-specific antibodies revealed similar patterns of hyperphosphorylation at the AT100 (Fig. 3F1,F2), Tau-1, and PT231 (data not shown) epitopes. Immunostaining for PS199, PS396, and PS404 epitopes was visibly altered in response to food deprivation (data not shown). These results conform with our Western blot data, which revealed large changes in tau phosphorylation at the Tau-1, AT8, AT100, and PT231 epitopes (Fig. $1 A, B a, B c-B e$ ) in response to food deprivation but smaller changes in phosphorylation at the PS199, PS396, and pS404 epitopes, which can be observed in control animals (Fig. $1 A, B b, B g, B h$ ). Similar patterns were observed in samples from insulin- and DG-injected mice (data not shown). The pattern of total tau was not altered during food-deprivation (Fig. 3G1,G2). The PS262, PS422, and Tau-C
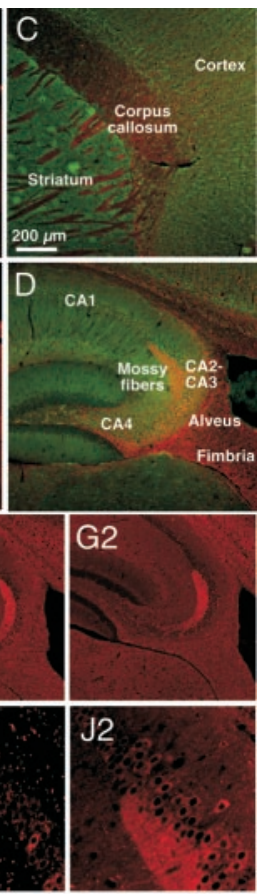

epitopes were not examined in anatomical sections, because antibodies against these epitopes cross-reacted with MAP2 on Western blots.

A closer examination of AT8 immunoreactivity in hippocampal $\mathrm{CA} 1$ and the CA2-3 junction revealed that food deprivation, insulin, and DG injections induced tau hyperphosphorylation predominantly in mossy fibers with little or no accumulation in somatodendritic portions of pyramidal neurons (Fig. 3H1,H2,I1,I2,J1,J2). Hyperphosphorylated tau also did not accumulate in the soma of dentate granule cells (data not shown). Thus, disruption of brain glucose led to tau hyperphosphorylation in axons.

\section{Alterations in glucose metabolism induce low body temperatures that correlate with \\ tau hyperphosphorylation}

We next looked for a possible correlation between circulating glucose and insulin and tau phosphorylation. Starvation caused significant drops in plasma glucose and insulin, which access to glucose prevented. Insulin injections increased insulin and decreased glucose levels. DG injections led to hyperglycemia, with no significant changes in insulinemia. No correlation between variations in plasma glucose or insulin and tau phosphorylation, when comparing the three experimental paradigms, was found (Table 2). Note that measurements of plasma glucose and insulin are usually taken after fasting to stabilize their levels. Because fasting can bring about tau hyperphosphorylation, we used nonfasted animals, hence the high variability observed in our animals. As stated in the Introduction, starvation, insulin, and DG treatment reportedly lower glucose metabolism. Thus, tau hyperphosphorylation observed during all of these treatments might be a consequence of altered glucose metabolism rather than circulating glucose and insulin levels per se. We also noticed lower rectal temperatures during all of the treatments. These drops, ranging from 7 to $10^{\circ} \mathrm{C}$, paralleled tau hyperphosphorylation (Table 2). Therefore, increased tau phosphorylation correlated with both diminished glucose metabolism and lower body temperatures.

\section{Low temperatures directly induce tau hyperphosphorylation in acute slices}

To discriminate the effects of reduced glucose metabolism and temperature on tau phosphorylation, we used metabolically active mouse brain slices. Incubation of slices at $37^{\circ} \mathrm{C}$ in DMEM, with or without $25 \mathrm{~mm}$ glucose, did not induce remarkable changes at the AT8 epitope (Fig. 4A1,A2,B). DG (25 mM) resulted in tau degradation and dephosphorylation, probably by inducing cell death (Fig. 4A3,B). Different concentrations and combinations of glucose and deoxyglucose did not result in detectable tau hyperphosphorylation (data not shown). Surprisingly, incubation at room temperature $\left(23^{\circ} \mathrm{C}\right)$ induced a very strong tau hyperphosphorylation, which was readily detectable after $5 \mathrm{~min}$. 
Table 2. Effect of starvation, insulin, or DG treatments on plasma glucose and insulin, rectal temperature, and tau phosphorylation

\begin{tabular}{|c|c|c|c|c|c|c|c|}
\hline & Glucose (mg/dl) & Var & Insulin (ng/ml) & Var & Temperature $\left({ }^{\circ} \mathrm{C}\right)$ & Var & P-Tau \\
\hline \multicolumn{8}{|l|}{ Starvation } \\
\hline Control & $183 \pm 14$ & $=$ & $2.3 \pm 1.3$ & $=$ & $37.9 \pm 0.2$ & $=$ & $=$ \\
\hline 3 d.S. & $115 \pm 17^{* *}$ & - & $0.1 \pm 0.1^{*}$ & - & $27.7 \pm 0.9^{* *}$ & - & + \\
\hline 3 d.S. plus glucose & $175 \pm 20$ & $=$ & $0.4 \pm 0.5$ & - & $37.5 \pm 0.2$ & $=$ & $=$ \\
\hline \multicolumn{8}{|l|}{ Insulin } \\
\hline Control & $224 \pm 19$ & $=$ & $3.6 \pm 0.6$ & $=$ & $36.9 \pm 0.4$ & $=$ & $=$ \\
\hline Insulin & $62 \pm 4^{* *}$ & - & $13.9 \pm 0.1^{* *}$ & + & $29.9 \pm 1.7^{* *}$ & - & + \\
\hline Insulin plus glucose & $60 \pm 1^{* *}$ & - & $13.8 \pm 0.6^{* *}$ & + & $35.5 \pm 0.9$ & $=$ & $=$ \\
\hline \multicolumn{8}{|l|}{ Deoxyglucose } \\
\hline Control & $183 \pm 46$ & $=$ & $1.0 \pm 0.2$ & $=$ & $36.9 \pm 0.4$ & $=$ & $=$ \\
\hline Deoxyglucose & $466 \pm 5^{* *}$ & + & $1.3 \pm 0.8$ & $=$ & $29.5 \pm 0.9^{* *}$ & - & + \\
\hline Glucose & $200 \pm 36$ & $=$ & $1.7 \pm 0.3$ & $=$ & $36.5 \pm 0.1$ & $=$ & $=$ \\
\hline
\end{tabular}

Var, Variations from the control condition; d.S., days starvation; $=$, no significant change; - , decrease; + , increase; \pm , slight increase; ${ }^{*} p<0.05 ; *^{* *} p<0.01$. Decreases in rectal temperature correlated with increases in tau phosphorylation for all of the treatments.

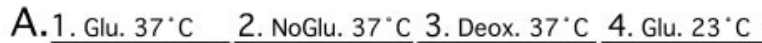

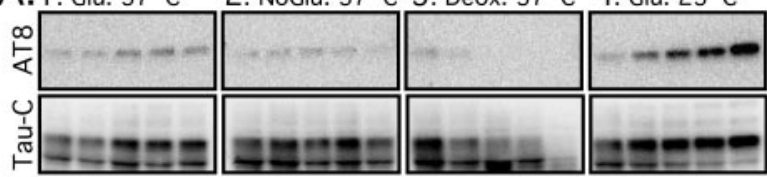

(min.) $05103060 \quad 0 \quad 5103060 \quad 0 \quad 5103060 \quad 0 \quad 5103060$

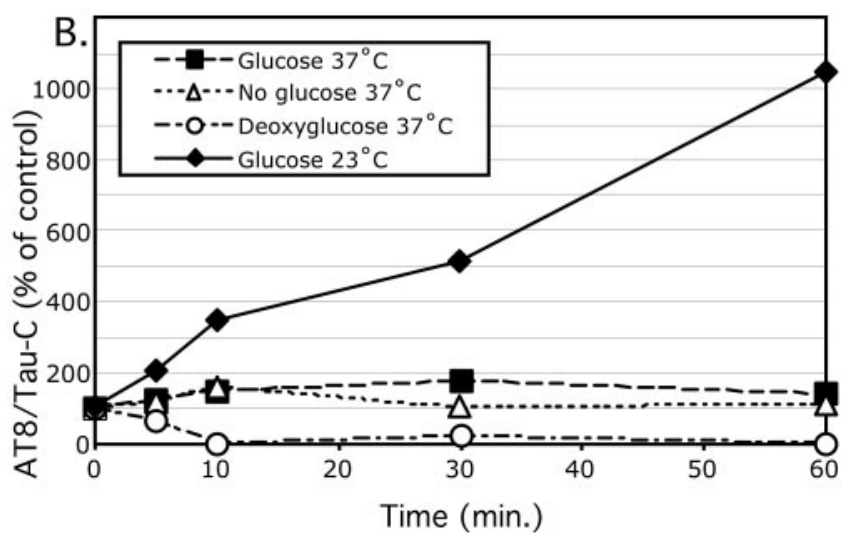

Figure 4. Kinetic of tau phosphorylation in brain slices. Western blot analysis of AT8 and Tau-C epitopes in mouse brain slices incubated at 0,5, 10, 30, and 60 min under different conditions is shown. $A 1-A 4$, DMEM with $25 \mathrm{~mm}$ glucose at $37^{\circ} \mathrm{C}(A 1)$, DMEM without glucose at $37^{\circ} \mathrm{C}(\mathrm{A2})$, DMEM with $25 \mathrm{~mm}$ deoxyglucose at $37^{\circ} \mathrm{C}(\mathrm{A3})$, and DMEM with $25 \mathrm{~mm}$ glucose at $23^{\circ} \mathrm{C}$ (A4). B, The intensities of AT8 bands in $A$ were normalized by Tau- $C$ and expressed as a percentage of 0 min incubation time. Two repetitions of this experiment led to similar results. Glu., Glucose; NoGlu., no glucose; Deox, deoxyglucose.

This increase in AT8 signal was paralleled by a shift in tau electrophoretic mobility similar to our in vivo results (Fig. 4A4,B).

Further characterization of this phenomenon showed that tau became highly phosphorylated at AT8 and PT231 as the temperature decreased from $37^{\circ} \mathrm{C}$ to reach a plateau between 20 and $30^{\circ} \mathrm{C}$ (Fig. $5 C, D, G$ ). At $15^{\circ} \mathrm{C}$, tau phosphorylation was still higher than at $37^{\circ} \mathrm{C}$, but at $1^{\circ} \mathrm{C}$ (on ice), tau was not hyperphosphorylated (Fig. $5 C, D, G$ ). Although not as dramatically as it was at AT8 and PT231, tau was hyperphosphorylated between 20 and $30^{\circ} \mathrm{C}$ at all other epitopes investigated in this study, with notable exception of AT100, which was not detected (Fig. 5A, B, E, G) (data not shown).

These results show that low temperatures can induce tau hyperphosphorylation directly. In brain slices, and in contrast to in vivo results, glucose deprivation did not affect tau phosphorylation states, and DG treatment resulted in tau dephosphorylation and degradation.

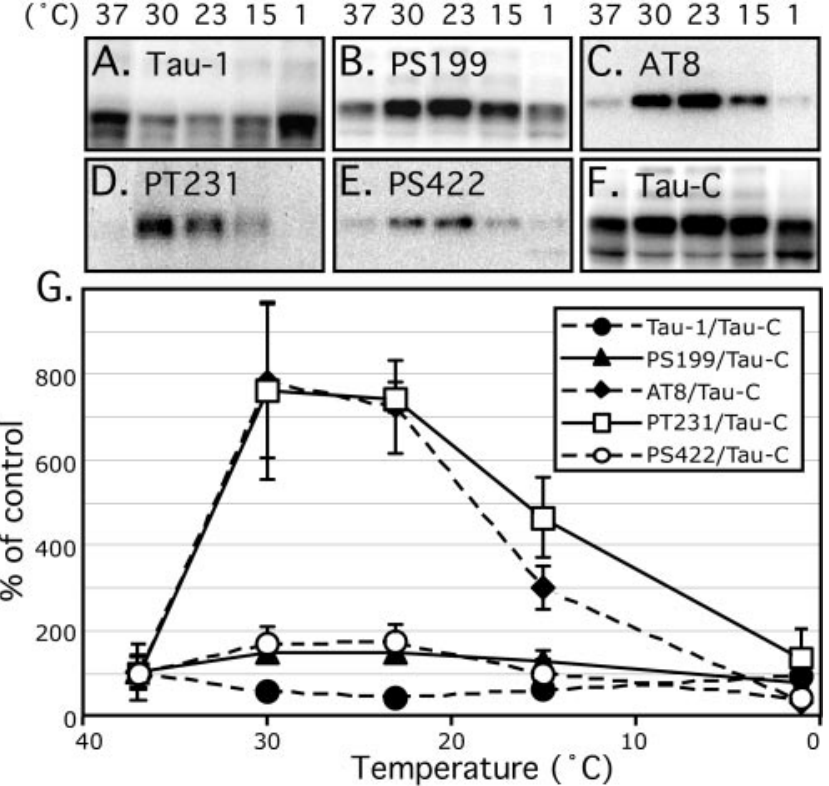

Figure 5. Characterization of the effect of temperature on tau phosphorylation in brain slices. Western blot analysis of mouse brain slices incubated in DMEM with $25 \mathrm{~mm}$ glucose for 60 $\min$ at $37,30,23,15$, and $1^{\circ} \mathrm{C}$ was analyzed at several tau epitopes. Each lane shows an immunoblot extract from one representative slice of three analyzed. A, Tau-1. B, PS199. C, AT8. D, PT231. E, PS422. F, Tau-C. G, The intensities of the bands in $A-E$ were normalized by Tau- $C$ and expressed as a percentage of incubation at $37^{\circ} \mathrm{C}$. Data are means $\pm S D ; n=3$.

\section{Inhibition of phosphatase activity during hypothermia is} responsible for tau hyperphosphorylation

Tau phosphorylation is the result of the balance between tau kinases and phosphatases. Thus, tau hyperphosphorylation during hypothermia could be attributable to either the activation of tau kinases or to the inhibition of phosphatases. To discriminate between these two possibilities, we examined the activities of brain phosphatases and tau kinases during hypothermia. PP1, PP2A, and PP2B are among the Ser-Thr PPs able to dephosphorylate tau in vitro. The activity of PP2A from brain extracts decreased exponentially at low temperatures (decay rate constant, $\left.15.7^{\circ} \mathrm{C} ; R^{2}>0.99\right)$. $\mathrm{PP} 2 \mathrm{~B}$ activity also decreased exponentially (data not shown; decay rate constant, $22.2^{\circ} \mathrm{C} ; R^{2}>0.97$ ). PP2A activity was inhibited by $\sim 35 \%$ at $30^{\circ} \mathrm{C}, \sim 60 \%$ at $23^{\circ} \mathrm{C}, \sim 72 \%$ at $15^{\circ} \mathrm{C}$, and $\sim 94 \%$ at $1^{\circ} \mathrm{C}$ (Fig. $6 \mathrm{~A}$ ). In contrast, the inhibition of tau kinases was linear (slope, $2.5 \% /{ }^{\circ} \mathrm{C} ; R^{2}>0.98$ ): $\sim 17 \%$ at $30^{\circ} \mathrm{C}, \sim 36 \%$ at $23^{\circ} \mathrm{C}, \sim 63 \%$ at $15^{\circ} \mathrm{C}$, and $\sim 88 \%$ at $1^{\circ} \mathrm{C}$ (Fig. $6 \mathrm{~A}$ ). Thus, hypothermia inhibited exponentially phosphatases and 
A.

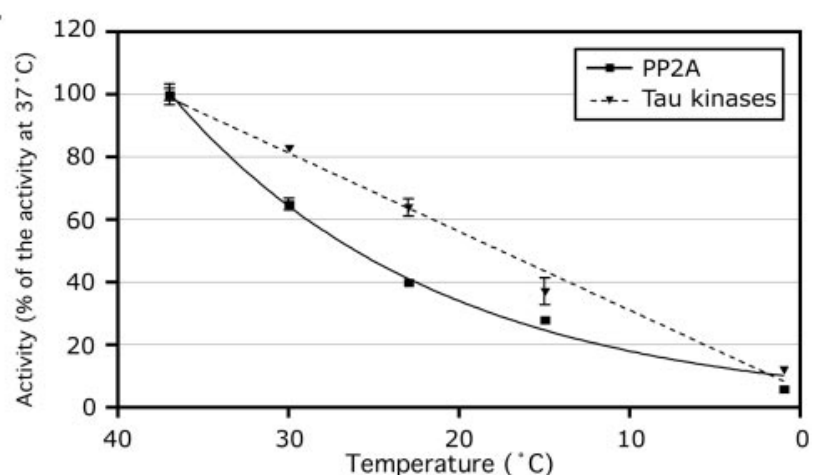

B.

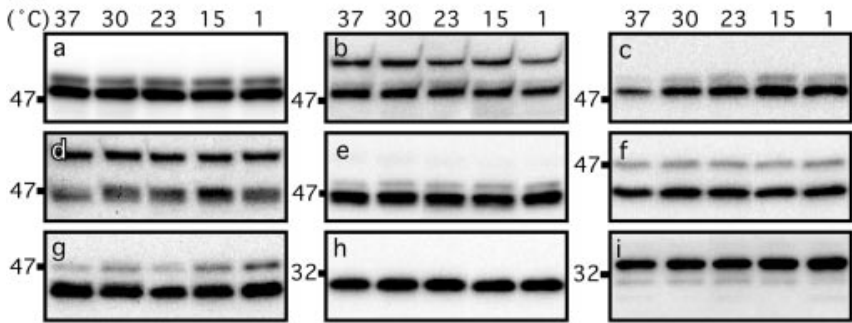

C.

('C) $37 \quad 30 \quad 23 \quad 15$

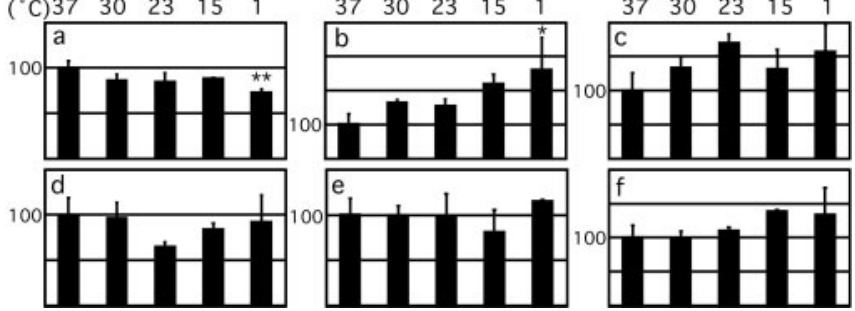

Figure 6. Effect of low temperatures on the activities of brain PP2A and tau kinases and on the activation of four tau kinases. A, PP2A activity from brain extract was assayed at different temperatures and expressed as a percentage of incubation at $37^{\circ} \mathrm{C}$ (solid squares, plain line). The best fit was exponential, with a decay rate constant of $15.7^{\circ} \mathrm{C}\left(R^{2}>0.99\right)$. The activity of brain tau kinases was assayed at different temperatures and expressed as a percentage of incubation at $37^{\circ} \mathrm{C}$ (solid triangles, dotted line). The best fit was linear, with a slope of $2.5 \% /{ }^{\circ} \mathrm{C}$ $\left(R^{2}>0.98\right)$. Data are means $\pm S D ; n=3 . B$, The activation state of four major tau kinases was assessed by quantitative Western blotting of the same samples as in Figure 5 , with antibodies recognizing the following kinases: $a$, GSK-3 $\beta ; b$, GSK-3 $\alpha / \beta$ [pY219/pY216] (active form); $c$ phospho-GSK-3 $\beta$ (Ser9, inactive form); $d$, SAPK/JNK; e, phospho-SAPK/JNK (T183/Y185, active form); $f$, p44/42 MAP kinase; $g$, phospho-p44/42 MAPK (T202/Y204, active form); $h$, cdk-5; $i$, p35. Each lane shows an immunoblot extract from one representative slice of three analyzed. $C$, The intensities of the bands in $B$ were quantified, normalized to the total kinase (except for $c \mathrm{dk} 5$ and p35), and expressed as a percentage of incubation at $37^{\circ} \mathrm{C} . a, \mathrm{GSK}-3 \beta \mathrm{pY} 216 / \mathrm{GSK}-3 \beta ; b$, GSK-3 $\beta$ Ser9/GSK-3 $\beta$; c, phospho-JNK/JNK (because phospho-p54 band was too faint, only p46 was quantified); d, phospho-MAPK/MAPK (p42 and p44 were quantified together); $e$, cdk5; $f$, p35. Data are means \pm SD; $n=3$.

linearly kinase activities. Our results suggest that the exponential inhibition by low temperature is a common characteristic of most ser-thr phosphatases. However, numerous studies have demonstrated that PP2A is likely to be the major regulator of tau phosphorylation in the mammalian brain, whereas $\mathrm{PP} 1$ and $\mathrm{PP} 2 \mathrm{~B}$ are minimally involved (Goedert et al., 1992; Bennecib et al., 2000; Gong et al., 2000; Planel et al., 2001; Tian and Wang, 2002). Therefore, it is the inhibition of PP2A during hypothermia that is likely to shift the delicate balance of tau phosphorylation toward hyperphosphorylation.

Although tau hyperphosphorylation during hypothermia can be simply explained by this difference of activities between tau kinases and phosphatases in vitro, it might not be the only factor inducing tau hyperphosphorylation in situ. For example, some major tau kinases could be activated at low temperatures. To investigate this possibility, we examined the activation of four major tau kinases at low temperatures. Among the kinases able to phosphorylate tau in vitro, GSK-3 $\beta$, cdk5, MAPK/extracellular signal-regulated kinase (ERK), and JNK are considered to be major physiological and pathological tau kinases (Maccioni et al., 2001; Planel et al., 2002; Zhu et al., 2002). We explored their activation patterns with specific antibodies in the same slice extracts used in Figure 5. Phosphorylation of GSK-3 $\beta$ at Tyr216 facilitates substrate binding, whereas phosphorylation at Ser9 leads to partial inhibition (Planel et al., 2002). Although mostly not significant, there was a tendency toward an inhibition of GSK-3 $\beta$ at low temperatures through the decrease of pY216 and increase of pS9 phosphorylation (Fig. $6 B a-B c, C a, C b$ ). Activated JNK (Fig. $6 B d, B e, C c$ ) and activated MAPK (Fig. $6 B f, B g, C d$ ) did not change significantly during exposure to low temperatures. Likewise, there were no significant changes in total GSK-3 $\beta$ (Fig. $6 B a$ ), total JNK (Fig. $6 B d$ ), or total MAPK (Fig. 6Bf) (quantification not shown). In the brain, cdk5 forms a heterodimer complex with the neuron-specific activator p35 (Maccioni et al., 2001). After cell death, p35 levels rapidly decrease as it is cleaved into $\mathrm{p} 25$, which further enhances cdk5 activity toward tau (Taniguchi et al., 2001; Hashiguchi et al., 2002). Independent of cell death, p35 can be degraded by the ubiquitin-proteasome pathway to lead to cdk5 inhibition without p25 formation (Saito et al., 1998; Bennecib et al., 2000; Planel et al., 2001). There were no significant changes in $\mathrm{cdk} 5$ and $\mathrm{p} 35$ during exposure at low temperatures (Fig. $6 B h, B i, C e, C f$ ), and there was no increase in the levels of p25 (data not shown). Thus, in brain slices, tau hyperphosphorylation at low temperatures is likely to be the result of the direct inhibition of phosphatase activity rather than the activation of tau kinases.

Finally, we also wanted to verify that the observed in vivo tau hyperphosphorylation was not attributable to kinase activation. We thus explored the activation patterns of the above four kinases in the same extracts used in Figure 1. Starvation resulted in the inhibition of GSK-3 $\beta$ at Ser9 site (Fig. $7 A a, B a$, lanes 1 and 2 ) and of cdk 5 by degradation of $\mathrm{p} 35$ without $\mathrm{p} 25$ formation (Fig. $7 A f, B f$, lanes 1 and 2). Activated MAPK did not change (Fig. $7 A d, B d$, lanes 1 and 2), but JNK was activated during starvation (Fig. $7 A c, B c$, lanes 1 and 2). These results confirm our previous study (Planel et al., 2001). Administration of glucose during starvation prevented hypothermia (Table 2 ) as well as JNK activation (Fig. $7 A c, B c$, lane 3 ) and 35 degradation (Fig. $7 A f, B f$, lanes 1 and $2)$. However, GSK-3 $\beta$ was still slightly phosphorylated at Ser9 (Fig. 7Aa,Ba, lane 3 ), probably as a result of a specific inhibition of the kinase during glucose-only diet. Insulin injections induced inhibition of GSK-3 $\beta$ (Fig. 7Cb,Db, lanes 1 and 2 ) and a slight activation of JNK (Fig. 7Cc,Dc, lanes 1 and 2), which could be prevented by concomitant injections of glucose (see lane 3). Activated MAPK, cdk5, and $\mathrm{p} 35$ did not change during the experiment (Fig. $7 C, D d-D f$, lanes $1-3$ ). The only significant changes in kinase activation during DG treatment were the inhibition of GSK-3 $\beta$ at Ser9 (Fig. 7Eb, Fb) and the inhibition of MAPK (Fig. $7 E d, F d)$, which is likely a specific effect of DG. Thus, during hypothermia, consequent to alterations of glucose metabolism in vivo, tau hyperphosphorylation is likely to be the result of the direct inhibition of phosphatase activity rather than the activation of tau kinases.

Together, our data demonstrate that low temperatures lead to the direct and rapid inhibition of phosphatase enzymatic activities, whereas major tau kinases are mostly not activated. These results 
suggest that the in vivo hypothermiainduced tau hyperphosphorylation is primarily attributable to direct PP2A inhibition by low temperature rather than to kinase activation.

\section{Prevention of hypothermia prevented tau hyperphosphorylation in vivo} If low temperatures are directly responsible for tau hyperphosphorylation during alterations of glucose metabolism, then preventing or rescuing hypothermia should prevent tau hyperphosphorylation. Thus, to further explore the role of temperature on tau phosphorylation in vivo, we placed animals in warmer ambient temperature. Insulin- and DG-treated mice were placed in a ventilated local at $37^{\circ} \mathrm{C}$ immediately after the injections. Starved mice were placed at $37^{\circ} \mathrm{C}$ for $2 \mathrm{hr}$ just before sampling. Brains were sampled, as indicated in Materials and Methods, with appropriate negative and positive controls. Placement at $37^{\circ} \mathrm{C}$ allowed the rectal temperature to stabilize around control values for all treatments (data not shown). No hyperphosphorylation was observed in insulin- or DG-treated mice, and hyperphosphorylation was reversed during starvation (Fig. $8 A-C$ ). Thus, tau hyperphosphorylation during starvation, insulin, or DG treatments can be completely prevented by normothermia.

\section{Discussion}

We investigated the in vivo relationship between glucose metabolism and tau phosphorylation. Although our preliminary results showed that starvation, insulin, or DG treatments could induce tau hyperphosphorylation with a biochemical, histochemical, and regional pattern similar to that reported for early $\mathrm{AD}$, we later learned that tau hyperphosphorylation was not caused by changes in glucose and insulin levels per se, but resulted mostly from hypothermia associated with altered glucose metabolism. We also demonstrated that low temperatures induce tau hyperphosphorylation by differential inhibition of kinase and phosphatase activities.

Although all treatments have different effects on the peripheral glucose and insulin contents (Table 2), they all lead to decreases in glucose metabolism in the brain as well as in the periphery. Thus, tau hyperphosphorylation is not caused by changes in circulating glucose or insulin per se, but is likely a consequence of altered glucose metabolism. However, this effect is indirect and the result of hypothermia because: (1) all of the treatments led to low rectal temperatures, (2) hypothermia alone was sufficient to induce tau hyperphosphorylation in acute brain slices, and (3) tau phosphorylation was completely restored to control values by maintaining the animals to normothermia. Because reduced glucose metabolism can lead to hypothermia (Scott et al., 1987), our results suggest that altered glucose metabolism induces tau hyperphosphorylation through hypothermia.

Although they did not pinpoint hypothermia as the cause of tau hyperphosphorylation, several other observations confirm its effects in vivo. For example, Arendt et al. (2003) have recently reported that hibernation, which is characterized by low metabolic rates and temperatures, induces tau hyperphosphorylation. General anesthesia is known to induce hypothermia, and ether anesthesia has been reported to induce tau hyperphosphorylation in mice (Ikeda et al., 2001). Moreover, cold-water swimming, which induces low body temperatures $\left(16.3 \pm 1.0^{\circ} \mathrm{C}\right.$ just after treatment, and $25.1 \pm 1.6^{\circ} \mathrm{C}$ after $30 \mathrm{~min} ; n=3$ ) (E. Planel, unpublished observations), also leads to rapid tau hyperphosphorylation in mice brains (Korneyev et al., 1995; Okawa et al., 2003). This effect is not caused by stress hormones, as demonstrated previously (Korneyev et al., 1995), but to hypothermia, because swimming in $37^{\circ} \mathrm{C}$ water does not induce tau hyperphosphorylation (E. Planel, unpublished observations).

These findings have important implications for the analysis of tau in laboratory animals. The mouse, with its high body surface area-to-mass ratio, is prone to body temperature imbalances (Horwitz et al., 2001). Some transgenic mice, like those carrying $\mathrm{A} \beta$ precursor protein mutations, seem especially vulnerable to hypothermia (Huitron-Resendiz et al., 2002; Iivonen et al., 2003). Therefore, when analyzing tau phosphorylation, the animal's body temperature should always be a consideration to avoid artifactual hypothermic tau hyperphosphorylation. Likewise, pre- 


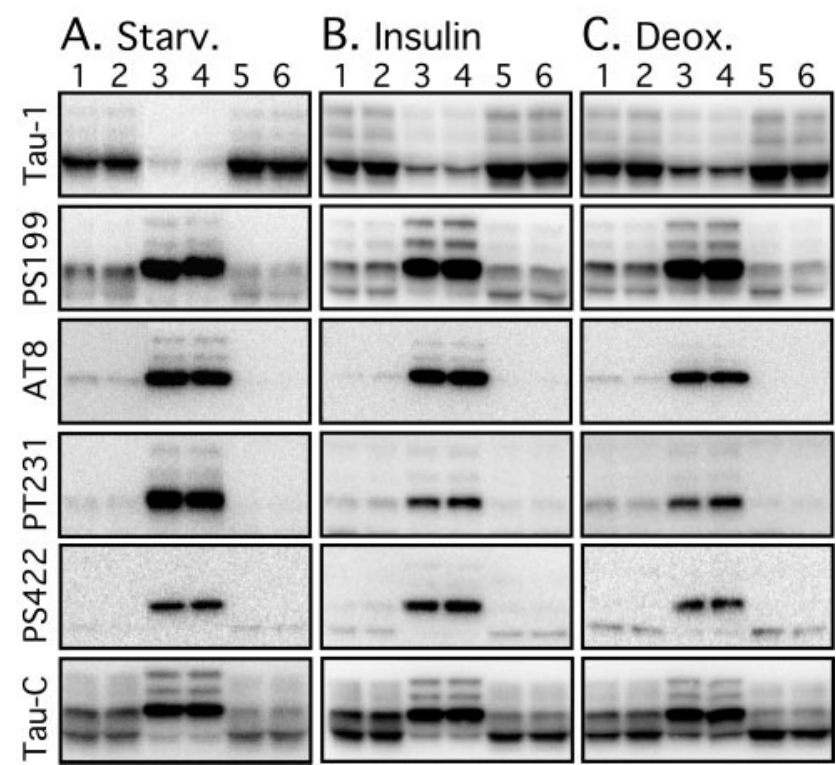

Figure 8. Effect of placement at $37^{\circ} \mathrm{C}$ on tau phosphorylation during starvation (Starv.), insulin, or DG (Deox.) treatments. Western blot of brains extracts from mice placed at $37^{\circ} \mathrm{C}$ after treatment is shown. Placement at $37^{\circ} \mathrm{C}$ allowed the rectal temperature to stabilize around control values for all treatments (data not shown). $A$, Starvation. B, Insulin injections. C, Deoxyglucose injections. Lanes 1 and 2, Controls; lanes 3 and 4, treatments; lanes 5 and 6, treatments and placement at $37^{\circ} \mathrm{C}$. Each lane represents one individual animal. Antibodies used are indicated on the left side.

cautions should be taken to minimize the time out of the incubator when using neuronal cultures.

Our data demonstrate that low temperatures led to the direct and exponential inhibition of brain phosphatases, whereas tau kinase activities decreased linearly. Moreover, in brain slices, hypothermia did not induce the activation of the four major tau kinases examined. Tau can be dephosphorylated by PP1, PP2A, and $\mathrm{PP} 2 \mathrm{~B}$ in vitro, but $\mathrm{PP} 2 \mathrm{~A}$ shows a much stronger ability in dephosphorylating tau (Goedert et al., 1992; Wang et al., 1996). Inhibitor studies in brain slices have demonstrated that PP2A is likely to be the main regulator of tau phosphorylation in vivo, whereas PP1 and PP2B are minimally involved (Bennecib et al., 2000; Gong et al., 2000). Moreover, PP2A expression is $\sim 15$ times more elevated than PP1 in the brain (Khew-Goodall and Hemmings, 1988), and there are numerous evidences supporting the role of PP2A as the major tau phosphatase in vivo (Tian and Wang, 2002). Last, we demonstrated that inhibition of PP2A, but not $\mathrm{PP} 1$ or $\mathrm{PP} 2 \mathrm{~B}$, is the factor inducing tau hyperphosphorylation during starvation (Planel et al., 2001). Thus, tau hyperphosphorylation in brain slices is probably attributable to the direct inhibition of PP2A by low temperatures.

The common change in kinase activation state in brain slices and in the three in vivo treatments was the inhibition of GSK-3 $\beta$ at Ser9. This result also confirms the role of phosphatases as powerful in vivo positive regulators of GSK-3 activity (Sutherland and Cohen, 1994; Planel et al., 2001). As reported previously, JNK was activated after $3 \mathrm{~d}$ of starvation. We also detected a slight activation of JNK $2.5 \mathrm{hr}$ after insulin injections but not after $1 \mathrm{hr}$ of DG treatment. These differences might be attributable to the duration or intensity of hypothermia. Interestingly, AT100 epitope was detectable during starvation, to a lesser extent during insulin treatment, but not during DG treatment. We recently demonstrated that JNK can participate to AT100 phosphorylation in cultured cells (Sato et al., 2002). Thus, JNK activation during starvation and insulin treatment might explain the phosphorylation of AT100 epitope. Together, these data suggest that during starvation, insulin, and DG treatments, tau hyperphosphorylation is primarily caused by the differential inhibition of PP2A by low temperatures, with JNK activation contributing to AT100 phosphorylation.

These results support the hypothesis that PP2A controls the phosphorylation state of tau in vivo (Sontag et al., 1996) and further strengthen the concept that in a context of reduced PP2A activity, normal or even reduced kinase activities are sufficient to induce the hyperphosphorylation of tau (Pei et al., 1997; Planel et al., 2001).

We show here that hypothermia induced by starvation, insulin, or DG injections led to a shift in the electrophoretic pattern of tau with a hyperphosphorylation at many of the phosphorylation sites found in AD, including the hyperphosphorylation of AT100 and PS422 epitopes that are highly characteristic of the AD-type abnormal tau phosphorylation (Matsuo et al., 1994; Hasegawa et al., 1996; Bussiere et al., 1999). We also demonstrated that hypothermia led to axonal tau hyperphosphorylation. In AD, careful observations have demonstrated that tau-positive dystrophic axons are widespread and can be easily detected in the alveus and fimbria of the hippocampus (Su et al., 1993). Also, the earliest detectable hyperphosphorylation of tau in $\mathrm{AD}$ is preferentially localized in neurites of vulnerable neurons and then extends to the soma ( $\mathrm{Su}$ et al., 1994), where it is considered to promote cytoskeletal changes that ultimately lead to NFT formation (Bancher et al., 1989; Braak et al., 1994; Trojanowski and Lee, 1994). Last, we found that abnormal tau hyperphosphorylation occurred in the cerebral cortex and hippocampus but to a lesser extent in the cerebellum. In AD, NFTs are observed in the hippocampus and neocortex but not the cerebellum (Larner, 1997).

Therefore, our data suggest that hypothermia-mediated inhibition of PP2A induced in vivo tau hyperphosphorylation with biochemical, histochemical, and regional patterns resembling those in early $\mathrm{AD}$ brains. These results are consistent with reports demonstrating that in vivo inhibition of phosphatases by okadaic acid (Arendt et al., 1998), or by expression of a dominantnegative mutant form of the catalytic subunit of PP2A (Kins et al., 2001), lead to abnormal tau hyperphosphorylation. PP2A is likely the major tau phosphatase in vivo, and its expression level and activity are decreased in AD brains (Gong et al., 1993, 1995; Vogelsberg-Ragaglia et al., 2001). Together, our results provide additional in vivo evidence for a crucial role of PP2A defects in abnormal tau hyperphosphorylation in $\mathrm{AD}$. The cause of the intrinsic resistance of the cerebellum to abnormal tau hyperphosphorylation is unknown, but may stem from the fact that the expression of PP2A PR55/B regulatory subunits is higher than in any other part of the brain (Schmidt et al., 2002).

Elder humans (as well as older rodents) reportedly regulate core temperature less efficiently than younger adults in hot or cold environments (Horwitz et al., 2001). In addition, many of the elderly humans have subnormal body temperatures (Fox et al., 1973; Keilson et al., 1985; Collins, 1992), and low body temperature has been proposed as a risk factor for $\mathrm{AD}$ (Holtzman and Simon, 2000). Our data support this hypothesis, with abnormal tau hyperphosphorylation as a molecular link.

Population-based and cohort studies have detected higher AD incidence rates in diabetes mellitus patients (Leibson et al., 1997; Ott et al., 1999). For example, the Rotterdam study shows that diabetes doubles the risk of $\mathrm{AD}$ and dementia [relative risk $(\mathrm{RR})=1.9$ ], and that insulin treatment, which is frequently complicated by hypoglycemic episodes, also doubles this risk $(\mathrm{RR}=$ 
4.3) (Ott et al., 1999). Diabetes is associated with impaired heat conservation (Neil et al., 1986; Scott et al., 1987), and overdoses of insulin lead to hypothermia and tau hyperphosphorylation. Thus, there is a possibility that diabetes and the potential hypoglycemic complications associated with insulin treatment enhance the risk of $\mathrm{AD}$ and dementia by promoting abnormal tau hyperphosphorylation through hypothermia.

In summary, we demonstrated for the first time that alterations in glucose metabolism can induce hypothermia leading to abnormal tau hyperphosphorylation through differential inhibition of kinase and phosphatase activities. Our work provides a mechanistic explanation for many previously unexplained observations and provides evidences for a central role of PP2A in the regulation of physiological and pathological tau phosphorylation. Finally, this work supports the concept that therapeutic strategies focused on reactivating metabolism may reduce the risk or retard the development of AD (Salehi and Swaab, 1999).

\section{References}

Alonso AC, Zaidi T, Novak M, Grundke-Iqbal I, Iqbal K (2001) Hyperphosphorylation induces self-assembly of tau into tangles of paired helical filaments/straight filaments. Proc Natl Acad Sci USA 98:6923-6928.

Arendt T, Holzer M, Fruth R, Bruckner MK, Gartner U (1998) Phosphorylation of tau, Abeta-formation, and apoptosis after in vivo inhibition of PP-1 and PP-2A. Neurobiol Aging 19:3-13.

Arendt T, Stieler J, Strijkstra AM, Hut RA, Rudiger J, Van der Zee EA, Harkany T, Holzer M, Hartig W (2003) Reversible paired helical filamentlike phosphorylation of tau is an adaptive process associated with neuronal plasticity in hibernating animals. J Neurosci 23:6972-6981.

Auer RN, Siesjo BK (1993) Hypoglycaemia: brain neurochemistry and neuropathology. Baillieres Clin Endocrinol Metab 7:611-625.

Bancher C, Brunner C, Lassmann H, Budka H, Jellinger K, Wiche G, Seitelberger F, Grundke-Iqbal I, Iqbal K, Wisniewski HM (1989) Accumulation of abnormally phosphorylated tau precedes the formation of neurofibrillary tangles in Alzheimer's disease. Brain Res 477:90-99.

Bennecib M, Gong C, Grundke-Iqbal I, Iqbal K (2000) Role of protein phosphatase-2A and -1 in the regulation of GSK-3, cdk5 and cdc2 and the phosphorylation of tau in rat forebrain. FEBS Lett 485:87-93.

Braak E, Braak H, Mandelkow EM (1994) A sequence of cytoskeleton changes related to the formation of neurofibrillary tangles and neuropil threads. Acta Neuropathol 87:554-567.

Bussiere T, Hof PR, Mailliot C, Brown CD, Caillet-Boudin ML, Perl DP, Buee L, Delacourte A (1999) Phosphorylated serine422 on tau proteins is a pathological epitope found in several diseases with neurofibrillary degeneration. Acta Neuropathol (Berl) 97:221-230.

Cheng B, Mattson MP (1992) Glucose deprivation elicits neurofibrillary tangle-like antigenic changes in hippocampal neurons: prevention by NGF and bFGF. Exp Neurol 117:114-123.

Cherel Y, Burnol AF, Leturque A, Le Maho Y (1988) In vivo glucose utilization in rat tissues during the three phases of starvation. Metabolism 37:1033-1039.

Collins KJ (1992) Temperature homeostasis and thermal stress. In: Oxford textbook of geriatric medicine (Evans JG, Williams F, eds), pp 93-100. Oxford: Oxford UP.

DeCarli C, Atack JR, Ball MJ, Kay JA, Grady CL, Fewster P, Pettigrew KD, Rapoport SI, Schapiro MB (1992) Post-mortem regional neurofibrillary tangle densities are related to regional cerebral metabolic rates for glucose during life in Alzheimer's disease patients. Neurodegeneration 1:113-121.

Fox RH, Woodward PM, Exton-Smith AN, Green MF, Donnison DV, Wicks MH (1973) Body temperatures in the elderly: a national study of physiological, social, and environmental conditions. Br Med J 1:200-206.

Frey KA, Minoshima S, Kuhl DE (1998) Neurochemical imaging of Alzheimer's disease and other degenerative dementias. Q J Nucl Med 42:166-178.

Goedert M, Cohen ES, Jakes R, Cohen P (1992) p42 MAP kinase phosphorylation sites in microtubule-associated protein tau are dephosphorylated by protein phosphatase 2A1. Implications for Alzheimer's disease [corrected]. [Erratum (1992) 313:203]. FEBS Lett 312:95-99.

Goedert M, Jakes R, Vanmechelen E (1995) Monoclonal antibody AT8 recognises tau protein phosphorylated at both serine 202 and threonine 205. Neurosci Lett 189:167-169.

Gong CX, Singh TJ, Grundke-Iqbal I, Iqbal K (1993) Phosphoprotein phosphatase activities in Alzheimer disease brain. J Neurochem 61:921-927.

Gong CX, Shaikh S, Wang JZ, Zaidi T, Grundke-Iqbal I, Iqbal K (1995) Phosphatase activity toward abnormally phosphorylated tau: decrease in Alzheimer disease brain. J Neurochem 65:732-738.

Gong CX, Lidsky T, Wegiel J, Zuck L, Grundke-Iqbal I, Iqbal K (2000) Phosphorylation of microtubule-associated protein tau is regulated by protein phosphatase $2 \mathrm{~A}$ in mammalian brain. Implications for neurofibrillary degeneration in Alzheimer's disease. J Biol Chem 275:5535-5544.

Gong CX, Lidsky T, Wegiel J, Grundke-Iqbal I, Iqbal K (2001) Metabolically active rat brain slices as a model to study the regulation of protein phosphorylation in mammalian brain. Brain Res Brain Res Protoc 6:134-140.

Gorell JM, Navarro CP, Schwendner SP (1981) Regional CNS levels of acetylcholine and choline during hypoglycemic stupor and recovery. J Neurochem 36:321-324.

Hasegawa M, Jakes R, Crowther RA, Lee VM, Ihara Y, Goedert M (1996) Characterization of mAb AP422, a novel phosphorylation-dependent monoclonal antibody against tau protein. FEBS Lett 384:25-30.

Hashiguchi M, Saito T, Hisanaga S, Hashiguchi T (2002) Truncation of CDK5 activator p35 induces intensive phosphorylation of Ser202/Thr205 of human tau. J Biol Chem 277:44525-44530.

Holtzman A, Simon EW (2000) Body temperature as a risk factor for Alzheimer's disease. Med Hypotheses 55:440-444.

Hong M, Lee VM (1997) Insulin and insulin-like growth factor-1 regulate tau phosphorylation in cultured human neurons. J Biol Chem 272:19547-19553.

Horton RW, Meldrum BS, Bachelard HS (1973) Enzymic and cerebral metabolic effects of 2-deoxy-D-glucose. J Neurochem 21:507-520.

Horwitz BA, Gabaldon AM, McDonald RB (2001) Thermoregulation during aging. In: Functional neurobiology of aging (Hof PR, Mobbs CV, eds), pp 839-854. New York: Academic.

Huitron-Resendiz S, Sanchez-Alavez M, Gallegos R, Berg G, Crawford E, Giacchino JL, Games D, Henriksen SJ, Criado JR (2002) Ageindependent and age-related deficits in visuospatial learning, sleep-wake states, thermoregulation and motor activity in PDAPP mice. Brain Res 928:126-137.

Iivonen H, Nurminen L, Harri M, Tanila H, Puolivali J (2003) Hypothermia in mice tested in Morris water maze. Behav Brain Res 141:207-213.

Ikeda Y, Ishiguro K, Fujita SC (2001) Ether stress induces tau hyperphosphorylation in the mouse brain. Neuroscience Res 39:S148.

Ishiguro K, Sato K, Takamatsu M, Park J, Uchida T, Imahori K (1995) Analysis of phosphorylation of tau with antibodies specific for phosphorylation sites. Neurosci Lett 202:81-84.

Keilson L, Lambert D, Fabian D, Thebarge J, Ackerson T, Palomaki G, Turgeon W (1985) Screening for hypothermia in the ambulatory elderly. The Maine experience. JAMA 254:1781-1784.

Khew-Goodall Y, Hemmings BA (1988) Tissue-specific expression of mRNAs encoding alpha- and beta-catalytic subunits of protein phosphatase 2A. FEBS Lett 238:265-268.

Kins S, Crameri A, Evans DR, Hemmings BA, Nitsch RM, Gotz J (2001) Reduced protein phosphatase 2a activity induces hyperphosphorylation and altered compartmentalization of tau in transgenic mice. J Biol Chem 276:38193-38200.

Korneyev A, Binder L, Bernardis J (1995) Rapid reversible phosphorylation of rat brain tau proteins in response to cold water stress. Neurosci Lett 191:19-22.

Kushner M, Tobin M, Alavi A, Chawluk J, Rosen M, Fazekas F, Alavi J, Reivich M (1987) Cerebellar glucose consumption in normal and pathologic states using fluorine-FDG and PET. J Nucl Med 28:1667-1670.

Larner AJ (1997) The cerebellum in Alzheimer's disease. Dement Geriatr Cogn Disord 8:203-209.

Leibson CL, Rocca WA, Hanson VA, Cha R, Kokmen E, O'Brien PC, Palumbo PJ (1997) Risk of dementia among persons with diabetes mellitus: a population-based cohort study. Am J Epidemiol 145:301-308.

Lesort M, Jope RS, Johnson GV (1999) Insulin transiently increases tau phosphorylation: involvement of glycogen synthase kinase-3beta and Fyn tyrosine kinase. J Neurochem 72:576-584.

Maccioni RB, Otth C, Concha II, Munoz JP (2001) The protein kinase Cdk5. Structural aspects, roles in neurogenesis and involvement in Alzheimer's pathology. Eur J Biochem 268:1518-1527. 
Matsuo ES, Shin RW, Billingsley ML, Van deVoorde A, O'Connor M, Trojanowski JQ, Lee VM (1994) Biopsy-derived adult human brain tau is phosphorylated at many of the same sites as Alzheimer's disease paired helical filament tau. Neuron 13:989-1002.

McCandless DW (1981) Insulin-induced hypoglycemic coma and regional cerebral energy metabolism. Brain Res 215:225-233.

Mielke R, Schroder R, Fink GR, Kessler J, Herholz K, Heiss WD (1996) Regional cerebral glucose metabolism and postmortem pathology in Alzheimer's disease. Acta Neuropathol (Berl) 91:174-179.

Neil HA, Dawson JA, Baker JE (1986) Risk of hypothermia in elderly patients with diabetes. Br Med J (Clin Res Ed) 293:416-418.

Newsholme EA (1976) Carbohydrate metabolism in vivo: regulation of the blood glucose level. Clin Endocrinol Metab 5:543-578.

Ohshima T, Ogawa M, Veeranna, Hirasawa M, Longenecker G, Ishiguro K, Pant HC, Brady RO, Kulkarni AB, Mikoshiba K (2001) Synergistic contributions of cyclin-dependant kinase 5/p35 and Reelin/Dab1 to the positioning of cortical neurons in the developing mouse brain. Proc Natl Acad Sci USA 98:2764-2769.

Okawa Y, Ishiguro K, Fujita SC (2003) Stress-induced hyperphosphorylation of tau in the mouse brain. FEBS Lett 535:183-189.

Ott A, Stolk RP, van Harskamp F, Pols HA, Hofman A, Breteler MM (1999) Diabetes mellitus and the risk of dementia: the Rotterdam study. Neurology 53:1937-1942.

Pei JJ, Tanaka T, Tung YC, Braak E, Iqbal K, Grundke-Iqbal I (1997) Distribution, levels, and activity of glycogen synthase kinase- 3 in the Alzheimer disease brain. J Neuropathol Exp Neurol 56:70-78.

Planel E, Yasutake K, Fujita SC, Ishiguro K (2001) Inhibition of protein phosphatase 2A overrides Tau protein kinase I/glycogen synthase kinase 3beta and Cyclin-dependant kinase 5 inhibition and results in tau hyperphosphorylation in the hippocampus of starved mouse. J Biol Chem 276:34298-34306.

Planel E, Sun X, Takashima A (2002) Role of GSK-3 beta in Alzheimer's disease pathology. Drug Dev Res 56:491-510.

Saito T, Ishiguro K, Onuki R, Nagai Y, Kishimoto T, Hisanaga S (1998) Okadaic acid-stimulated degradation of p35, an activator of CDK5, by proteasome in cultured neurons. Biochem Biophys Res Commun 252:775-778.

Salehi A, Swaab DF (1999) Diminished neuronal metabolic activity in Alzheimer's disease. Review article. J Neural Transm 106:955-986.

Sato S, Tatebayashi Y, Akagi T, Chui DH, Murayama M, Miyasaka T, Planel E, Tanemura K, Sun X, Hashikawa T, Yoshioka K, Ishiguro K, Takashima A (2002) Aberrant tau phosphorylation by glycogen synthase kinase-3beta and JNK3 induces oligomeric tau fibrils in COS-7 cells. J Biol Chem 277:42060-42065.

Schmidt K, Kins S, Schild A, Nitsch RM, Hemmings BA, Gotz J (2002) Diversity, developmental regulation and distribution of murine PR55/B subunits of protein phosphatase 2A. Eur J Neurosci 16:2039-2048.
Scott AR, Bennett T, Macdonald IA (1987) Diabetes mellitus and thermoregulation. Can J Physiol Pharmacol 65:1365-1376.

Sontag E, Nunbhakdi-Craig V, Lee G, Bloom GS, Mumby MC (1996) Regulation of the phosphorylation state and microtubule-binding activity of Tau by protein phosphatase 2A. Neuron 17:1201-1207.

Stein DJ, Buchsbaum MS, Hof PR, Siegel Jr BV, Shihabuddin L (1998) Greater metabolic rate decreases in hippocampal formation and proisocortex than in neocortex in Alzheimer's disease. Neuropsychobiology 37:10-19.

Su JH, Cummings BJ, Cotman CW (1993) Identification and distribution of axonal dystrophic neurites in Alzheimer's disease. Brain Res 625:228-237.

Su JH, Cummings BJ, Cotman CW (1994) Early phosphorylation of tau in Alzheimer's disease occurs at Ser-202 and is preferentially located within neurites. NeuroReport 5:2358-2362.

Sutherland C, Cohen P (1994) The alpha-isoform of glycogen synthase kinase-3 from rabbit skeletal muscle is inactivated by p70 S6 kinase or MAP kinase-activated protein kinase-1 in vitro. FEBS Lett 338:37-42.

Szendrei GI, Lee VM, Otvos Jr L (1993) Recognition of the minimal epitope of monoclonal antibody Tau-1 depends upon the presence of a phosphate group but not its location. J Neurosci Res 34:243-249.

Taniguchi S, Fujita Y, Hayashi S, Kakita A, Takahashi H, Murayama S, Saido TC, Hisanaga S, Iwatsubo T, Hasegawa M (2001) Calpain-mediated degradation of p35 to p25 in postmortem human and rat brains. FEBS Lett 489:46-50.

Tian Q, Wang J (2002) Role of serine/threonine protein phosphatase in Alzheimer's disease. Neurosignals 11:262-269.

Trojanowski JQ, Lee VM (1994) Paired helical filament tau in Alzheimer's disease. The kinase connection. Am J Pathol 144:449-453.

Vogelsberg-Ragaglia V, Schuck T, Trojanowski JQ, Lee VM (2001) PP2A mRNA expression is quantitatively decreased in Alzheimer's disease hippocampus. Exp Neurol 168:402-412.

Wang JZ, Grundke-Iqbal I, Iqbal K (1996) Restoration of biological activity of Alzheimer abnormally phosphorylated tau by dephosphorylation with protein phosphatase-2A, -2B and -1. Brain Res 38:200-208.

Yanagisawa M, Planel E, Ishiguro K, Fujita SC (1999) Starvation induces tau hyperphosphorylation in mouse brain: implications for Alzheimer's disease. FEBS Lett 461:329-333.

Zheng-Fischhofer Q, Biernat J, Mandelkow EM, Illenberger S, Godemann R, Mandelkow E (1998) Sequential phosphorylation of tau by glycogen synthase kinase-3beta and protein kinase A at Thr212 and Ser214 generates the Alzheimer-specific epitope of antibody AT100 and requires a paired-helical-filament-like conformation. Eur J Biochem 252:542-552.

Zhu X, Lee HG, Raina AK, Perry G, Smith MA (2002) The role of mitogenactivated protein kinase pathways in Alzheimer's disease. Neurosignals $11: 270-281$. 